\section{FORESTRY IN BRITISH COLONIAL TERRITORIES}

\begin{abstract}
$\mathrm{N}$ the Forest Administration Report for Nigeria (Gov. Printer, Lagos, 1945; London: Crown Agents for the Colonies. 4s.) it is stated that in future the forest year will close at the end of March instead of at the end of December, due to the fact that at the end of December most of the forest work carried out in the cold-weather season is only half completed. In India the close of the forest year has always been March 31 for the same early recognized reason. The report in question, therefore, is dated from January 1,1944 , to March 31,1945 . In it we read that yet another revision of the forest policy of the Government was approved in February, 1945. The objects are briefly summed up. Since subsistence farming by a rapidly incrensing population is the major industry of the country, the forest policy aims at preserving the climatic and physical condition of the country, its soil fertility and its water supplies by the maintenance and improvement of the vegetation cover, and at supplying in perpetuity and as cheaply as possible all the forest produce both as raw material and as the product of forest industries, required for the well-being of the inhabitants of the country.

Because of the growing demand in Nigeria for land for cultivation, it is essential that the forest estate should be secure, well distributed, and intensively managed, and that exploitation be controlled and improved and forest industries initiated and developed to prevent waste of land or produce. A ten-year plan of development detailing the staff and expenditure required to give full effect to the policy was submitted during the year, and is still under consideration.
\end{abstract}

Even before the War, but particularly during its preoccupations, inadequate staff has resulted in farming encroachments in reserves; so much so that a certain area of previously reserved forests has now been lost. It is said that as opportunities begin to increase for the necessary stock-taking, it has become depressingly obvious that only a much increased protective staff, firmer deterrents by adequate penalties in the courts and a more rigorous attitude on the part of Government in its reservation policy and practice will check these alarming forest depredations. Among other Iosses of forest, the Benin Native Administration has had to excise 396 sq. miles which have been so much farmed as to be no longer productive forest. In this connexion a remark is noted by the Conservator of Forests, N.E. Circle, on revisiting the area of the Benin Forest where he had practised sylviculture for some years. "I should like to place on record that I have never seen such extensive forest destruction anywhere to compare with that which has taken place in the unreserved forests of Benin Division during the last ten years. It is indeed fortunate that more than $50 \%$ of the forests of the Division have already been reserved. Forest reserves scarcely require to be demarcated now, because they stand out so prominently in the landscape." Other considerable excisions of so-called forest reserves have had to be made in other parts of Nigeria. The report states that: "The reserves, approved many years ago, have in numerous cases not been clearly demarcated and described, and they are steadily being whittled away by the encroachments of farmers. Persistent and continuous efforts to consolidate what remains of the forest, which is essentially the last local source of timber and fuel for a rapidly increasing population, have consistently failed. They will continue to fail if the Department cannot obtain administrative support in resisting the truculent demands of the improvident cultivators. There is admittedly very definite land hunger in this Province, but the relinquishment of all forest land for agriculture will not relieve the pressure for more than a few years, while the production of timber and fuel on land degraded by continuous cultivation and incapable of producing food will then be difficult and expensive."

In the Report for the Forestry Department, Nyasaland, to the end of December, 1945 (Zomba : Gov. Printer, 1946), it stated that the activities of the Department during the year were mainly devoted to maintenance and consolidation of progress already achieved. Proposals for planting schemes in various native areas, mainly for firewood production, were considered by several district development committees, and in most cases endorsed. It is thought that such short-term schemes can usually be financed either by native treasuries or by grants from the local native development and welfare fund. On the other hand, long-term schemes in native areas for the production of major timber will generally require assistance from funds provided under the Colonial Development and Welfare Act, 1945. A pre-requisite, however, for all further forestry development is an increase in the European staff and a local school for training Africans in forestry. An urgent need is to impress on the large African population the principle that payment will have to be made by the people for the ultimate produce derived from forest plantations, and that for the large majority of village communities the only alternative to planting schemes is for them to maintain adequate village forest areas (natural woodland) from which produce may be taken free of charge in return for the free communal labour given in the protection and simple management of the areas.

A committee was set up by Government to make recommendations concerning the legislation which is required to ensure the conservation and improvement of the natural resources of the Protectorate. Recommendations were submitted to Government in the form of a bill introduced at the session of the Legislative Council held in December. The proposed legislation has an important bearing on forest policy, and is greatly welcomed by the Forestry Department.

An interesting item of information of possibly considerable value in the future is contained in the following extract : "Certain areas of the Rift Valley escarpment in Dowa and Dedza district are assuming an increasing importance as a source of bamboos for commercial purposes, the manufacture of tobacco baskets being one of the main items. In order to effect greater control over this trade a bamboo market was established by the Department at Mvera on the Dowa escarpment, and its success was reflected in a great increase in sales of bamboos from the region. It is hoped to set up bamboo markets at other centres. Villagers, of course, come from afar to these escarpments to take bamboos free of charge for their own domestic requirements. Very large numbers of dead bamboos, following a gregarious seeding, are available for cutting in Mua-Livulezi forest reserve near the railway in Dedza district. Local demand is only small and undoubtedly there is scope here for commercial enterprise." 
The Administration Report to the end of 1945 of the Conservator of Forests, Trinidad and Tobago (Gov. Printer, Trinidad, 1946), makes interesting reading. In some ways Trinidad has made considerable progress as compared with other forest services under the Colonial Office; not the least, perhaps, in the fact that a number of the forests of the country are under 'working plans' which provide some form of elementary yield control ; and even in more or less inaccessible reserves of the Northern Range, which are not yet under working plans, girth limits are in force wherever exploitation takes place. Further, all 'working circles' subjected to concentrated regeneration are governed by working plans. The main factor which is brought about by this position is that the amount of excessive war fellings made during the last seven or eight years will be known and, if necessary, future exploitation regulated in the areas which have suffered, just as is the case in India. This reflects considerable credit on the forest administration of the Colony and the Colonial Government. There are one or two matters, however, in which the Forest Department does not appear as yet to have found itself. It appears to have come to the conclusion that imports of a certain type of forest produce will always be necessary, owing to the fact that exploitation of tropical forest is very costly, and that even the mora forests do not appear to offer great prospects as had once been hoped. On these subjects the report states as follows:

"Whilst the utilisation of local lumber generally has not yet reached the maximum production permissible, for supplies of properly seasoned lumber cut to a variety of standard dimensions, the Colony is dependent upon imports mainly of pitch pine, white pine and douglas fir. No supply of this type of local lumber is available other than small stocks held by furniture makers and private persons for their own use. Adverse factors such as the high cost of exploitation due to low volume production per acre, high loss in conversion of tropical woods, and high cost of labour in relation to skill and output render it unlikely that any such supply from the natural mixed forests could compete with imports. Expert opinion differs as to the economics of intensive exploitation of the mora forests, adverse factors being a high conversion wastage and the refractory nature of mora as a timber. The Colony is likely, therefore, to be dependent upon imports for the higher grade building market until the regenerated forests commence to yield regular supplies of timber at a high rate of volume per acre and consequent low cost of exploitation. Much more intensive exploitation of the forests could, however, be secured by the production of veneers for plywood manufacture. Before this can be undertaken, however, it is necessary to be sure of an adequate supply of raw material, which in turn depends upon how many of the local species will veneer satisfactorily."

In connexion with the introduction of the rotary saw or peeler of the plywood mill into the exploitation of the tropical forest question, it by no means appears necessary that a large percentage of the species of timber in the forest should be capable of peeling; it is not only the veneers from the more valuable tropical species that count, but also the poorer class timbers which are peeled to form the inner sheets; the veneers, of course, only occupying the outside. In any event, testing for peeling purposes of a certain number of the forest species should prove comparatively easy, as they could be sent to the Forest Products Research
Station at Princes Risborough, or possibly to one of the United States research institutes. This would appear to be a practical piece of work which should be given early precedence.

Underlying most of the forestry reports from the British Empire at the present time is the recurrent statement stating that the departments are very much under-manned, and that really important work which should be put in hand to secure future progress must be held up until trained staff in sufficient numbers is available.

\section{MUSICAL ACOUSTICS CONFERENCE AT LIÈGE}

$I^{1}$ $\mathrm{N}$ connexion with the recent celebrations of the centenary of the Faculty of Applied Science of the University of Liège and of the Engineers' Association connected therewith, a conference of persons interested in musical and dramatic acoustics was held during September 4-5 in that city. The sessions were held under the presidency of F. Dacos, and the arrangements were in the hands of F. Monfort. They consisted of five lectures by specialists in various aspects of the subject, followed by general discussions in which both men of science and musicians took part.

M. Fouché (Istambul) dealt with the theory of wind instruments. The natural frequencies of columns of air of various types-pipes with sideholes, partially stopped pipes, etc.-are worked out using the analogy with electrical circuits, the 'endcorrection' appearing as a form of radiation resistance. For reed pipes the resonant frequencies of the system, reed plus column of air, are calculated and the results discussed in the light of the intonation of instruments like the clarinet. It was pointed out that these problems date back to some experiments performed by the brothers Weber in 1827.

G. van Esbroeck (Ghent) contributed a paper on the history of musical scales. He pointed out that it is not the ear which has dictated the series of tones which an instrument with fixed notes is made to produce ; on the contrary, the tuning of such instruments has conditioned the education of the 'musical ear'. Thus our present scales are based on the Pythagorean tuning of the cithara, a stringed instrument of the ancient Greeks. The demands of key modulation, however, have forced a compromise with just intonation in the form of tempered scales. In the discussion that followed, it was pointed out that singers and players on free-note instruments like the violin use individual scales partly to suit the context or line of music and partly as a result of their musical education.

E. G. Richardson (Newcastle-on-Tyne) outlined the theory of coupled vibrations and of transient phenomena in the production of tone by musical instruments. The action of the hammer on a pianoforte string may be likened to the closing of an inductive switch in a primary electric circuit of which the secondary is a cable. The flute and the flue pipes of organs represent coupled systems in which the exciting member (the edge tone at the mouth) is very strongly damped in comparison with the other (the air column), whereas in an organ reed pipe, and still more in the human voice, the reverse is the case. In the first few milliseconds after the excitation of such a system, transients are set up, the wave form of which may be 